Journal of Advanced Research in Fluid Mechanics and Thermal Sciences

\title{
Experimental Investigation on The Effect of Divergent Tower Solar Chimney on The Theoretical Power Potential
}

\author{
Ahmad Jawad ${ }^{1}$, Mohd Suffian Misaran ${ }^{1, *}$, Md. Mizanur Rahman ${ }^{2, *}$, Mohd Azlan Ismail $^{1}$ \\ Faculty of Engineering, Universiti Malaysia Sabah (UMS), Malaysia \\ Mechatronics Engineering Department, World University Bangladesh, Bangladesh
}

\section{ARTICLE INFO}

\section{Article history:}

Received 4 November 2020

Received in revised form 1 February 2021

Accepted 4 February 2021

Available online 16 March 2021

Keywords:

Solar Energy; Solar Chimney; Divergent Chimney; Performance Enhancement

\section{ABSTRACT}

Solar chimney power plant is a sustainable alternative for electricity generation using solar as the source of energy. In general, the main body of a solar chimney plant requires a tall structure which is costly and challenging to construct. Thus, it is important to increase the performance of the solar chimney power plant and have a better energy-cost ratio. This study aims to experimentally investigate the influence of divergent solar chimney as opposed to a cylindrical chimney on solar chimney performance. Three divergent scaled-down solar chimney model at 1-meter, 1.5-meter and 2-meter were fabricated and tested for its performance at various simulated heat loads. The test results were compared with similar heights cylindrical solar chimney. The experiments show that divergent solar chimney increases the theoretical power generation potential and improves the stalk effect and have higher outlet velocity compared to a cylindrical solar chimney. The power potential of the divergent chimney is increased up to 18 times with the maximum theoretical power obtain at $0.183 \mathrm{~W}$ on the 2-meter divergent chimney. Higher temperature was recorded on the 2-meter divergent chimney outlet at $341.3 \mathrm{k}$ compared to $330.4 \mathrm{k}$ on the cylindrical chimney indicates better stack effect. The highest average velocities in the divergent and cylindrical chimneys were recorded under the electric heat load of $2 \mathrm{~kW}$ at $0.994 \mathrm{~m} / \mathrm{s}$ and $0.820 \mathrm{~m} / \mathrm{s}$ respectively in the 1-meter configuration. It is also observed that the air velocity in a shorter divergent chimney is higher than taller divergent chimney models while better compared to all cylindrical height. This study finds that a shorter divergent solar chimney produces greater energy compared to a higher cylindrical solar chimney. Therefore, it is possible to reduce the overall cost of solar chimney by reducing the height of the main structure without sacrificing the performance of the solar chimney.

\section{Introduction}

Solar energy has been used for centuries as it is one of the most reliable and sustainable sources of energy available. The most common form of solar energy would be Solar PV systems; however, the systems does have its fair share of disadvantage such as efficiency degradation over time and

\footnotetext{
* Corresponding author.

E-mail address: suffian@ums.edu.my

* Corresponding author.

E-mail address: mizanur.rahman@mte.wub.edu.bd
}

https://doi.org/10.37934/arfmts.81.1.140149 
toxic materials used. Alternatively, a solar chimney power plant (SCPP) uses solar radiation to generate electric power as well as a hybrid system using secondary waste heat from a plant or a geothermal, without the quirks of a solar PV system. This allows the SCPP systems to operate continuously day and night at moderate weather. Solar chimney power plant working principle is simple; solar collectors gather solar radiation to heat the air, this hot air naturally rises upwards due to the buoyancy effect channelled to the chimney. Bladed turbine mounted inside the chimney converts kinetic energy into mechanical energy and generate electric power in the generator. The hot air is released harmlessly to the surrounding air from the chimney outlet at several hundred meters above base.

A first functional prototype of solar chimney was launched in Spain in the year of 1982 it lasts for 8 years has chimney height of 195 meters long and while diameter was 10 meters wide and had generating capability of $50 \mathrm{~kW}$ [8]. Solar chimney power plants projects generally less successful, cancelled, and postponed due to high capital cost and limited power generation capability. This motivates researchers to study ways of reducing cost caused by the structure size and boost the performance of solar chimney power plant. Fasel et al., [7] studied several scaled versions of the Manzanares prototype using CFD method, the study suggests that power generation increases with the increment of chimney height and solar collector size of solar chimney power plants. Various approach has been proposed to reduce the cost associated with the solar chimney main structure. Papageorgiou [16] introduced the concept of the floating chimney made with fabric that is costeffective and safe during an earthquake, however, crosswinds can deflect the chimney affecting the chimney performance. Aurybi et al., [2] propose a solar chimney integrated with a thermal power plant, it uses the hot waste flue gas as a heat source to operate the solar chimney during night time or at low solar radiation intensity [2]. Hu and Leung [9] and Hu et al., [10] performed numerical solution on cylindrical, divergent and various shape of diffuser chimney. Numerical outcomes conclude that divergent shaped chimney is 13 times more efficient than the cylindrical chimney [10]. Moreover, the study validated numerical solution with outcomes obtained from the CFD performed on a divergent shaped chimney with different area ratios and cylindrical chimney, the results suggest a 100 -meter divergent chimney can generate $380 \mathrm{~kW}$ which exceed the power generated by a 200 meter and 300-meter cylindrical chimney [9]. Convergent chimney performance was also studied by several researchers $[17,19]$. The study concludes divergent chimney is more efficient compared to a convergent shaped chimney because it has higher kinetic energy at the base where the turbine is located $[13,17]$. Furthermore, high velocity at the exits of the chimney equates to low pressure possibly causing chocking phenomena [15].

Current literature has reported the advantage of using divergent solar chimney using simulated results, however, few laboratory experiments on the subject are available. Thus, this study aims to experimentally investigate the performance of divergent solar chimney compared to a cylindrical chimney in a laboratory condition.

\section{Methodology}

A scaled-down model of the solar chimney was designed and fabricated in the lab based on the physical dimension of the Manzanares prototype SCPP as shown in Table 1. The natural buoyancy equation was used to calculate the theoretical air velocity inside the chimney as shown in Eq. (1) [18]. And the diameter of the chimney was calculated using the Fourier Equation as shown in Eq. (2) [6]. 


\section{Table 1}

Physical Parameters of Manzanares Prototype

\begin{tabular}{lllll}
\hline Height $(\mathrm{m})$ & Diameter $(\mathrm{m})$ & Air velocity $(\mathrm{m} / \mathrm{s})$ & Temperature difference $(\mathrm{K})$ & Ambient Temperature $(\mathrm{k})$ \\
\hline 194.6 & 10 & 9.1 & 20 & 293 \\
\hline
\end{tabular}

$v=\sqrt{\frac{2 g h \Delta T}{T_{\infty}}}$

$f r=\frac{v}{\sqrt{g D}}$

Ahmed and Patel [1] reported that the divergent chimney performance is optimal at the throat angle of $2^{\circ}$. Thus, the divergent shaped chimney was designed and fabricated with the throat angle fixed at $2^{\circ}$. Bellmouth parameters were obtained using Eq. (3) [12]. Figure 1 shows the important dimensions of a diverged solar chimney.

$$
\begin{aligned}
& B M_{h}=0.2 \sim 0.8 \times D_{h} \\
& B M_{r}=0.2 \sim 0.4 \times D_{h}
\end{aligned}
$$

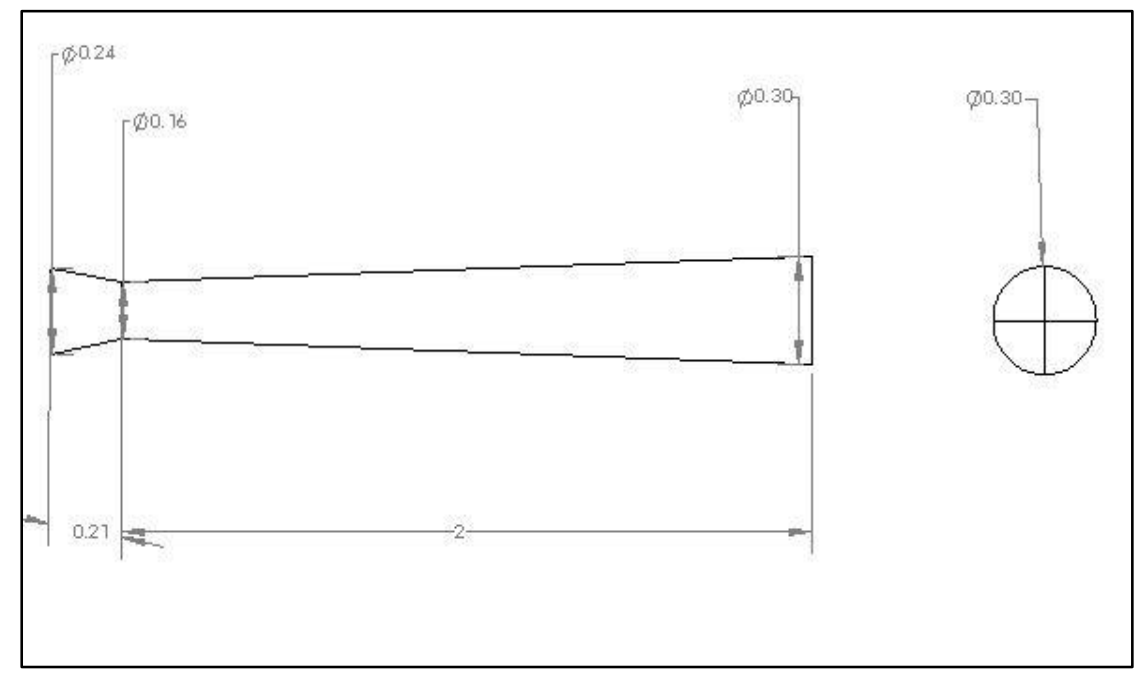

Fig. 1. Schematic Figure of a Divergent Chimney

The final dimension of the scaled-down model of the Manzanares Solar Chimney is as shown in Table 2. This study designed and fabricated 3 solar chimney model; 1-meter, 1.5-meter and 2-meter diverged solar chimney as shown in Figure 2(a).

Three matching cylindrical chimney model were experimented as well to study and compare the performance of each chimney compared to the equivalent divergent chimney. The height and diameter of cylindrical solar chimney models are as shown in Table 2.

Table 2

Dimension for The Chimney Models

\begin{tabular}{lllll}
\hline Height $(\mathrm{m})$ & \multicolumn{2}{l}{ Divergent Chimney } & & \multicolumn{2}{c}{ Cylindrical Chimney } \\
& Diameter $(\mathrm{m})$ & Bellmouth Height $(\mathrm{m})$ & Bellmouth Diameter $(\mathrm{m})$ & Diameter $(\mathrm{m})$ \\
\hline 2 & 0.3 & 0.21 & 0.24 & 0.28 \\
1.5 & 0.23 & 0.161 & 0.092 & 0.21 \\
1 & 0.15 & 0.105 & 0.06 & 0.14 \\
\hline
\end{tabular}




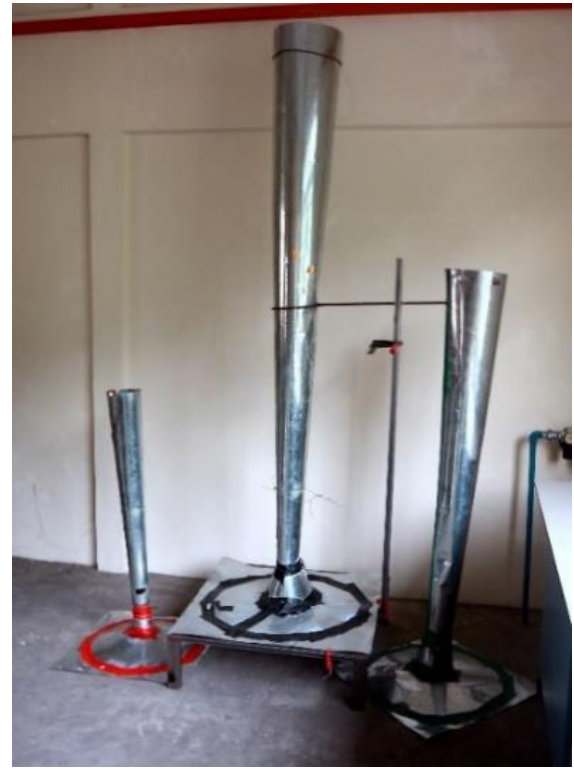

(a)



(b)

Fig. 2. (a) Divergent Chimneys (b) Cylindrical Chimneys

In this experiment, heating coil of $2 \mathrm{~kW}$ was used as a replacement heat source located at the inlet of the chimney. Voltage regulator and digital multimeter were used to control the required electric heat load which is varied from $0.9 \mathrm{~kW}$ to $2.0 \mathrm{~kW}$. The exit air velocity was measured using an anemometer model CENTER 330. The temperature variation was measured using K-type thermocouple and a data logger model 18200-40 (Cole Palmer). Four thermocouples were located in the following location; inside the chimney (T1), exit of the chimney (T2), 10 centimetres above the exit of the chimney (T3) and ambient lab temperature (T4). All the thermocouples were further attached with a data logger which was set to record temperature reading at every five seconds. The schematic diagram of the experimental setup is as shown in Figure 3.

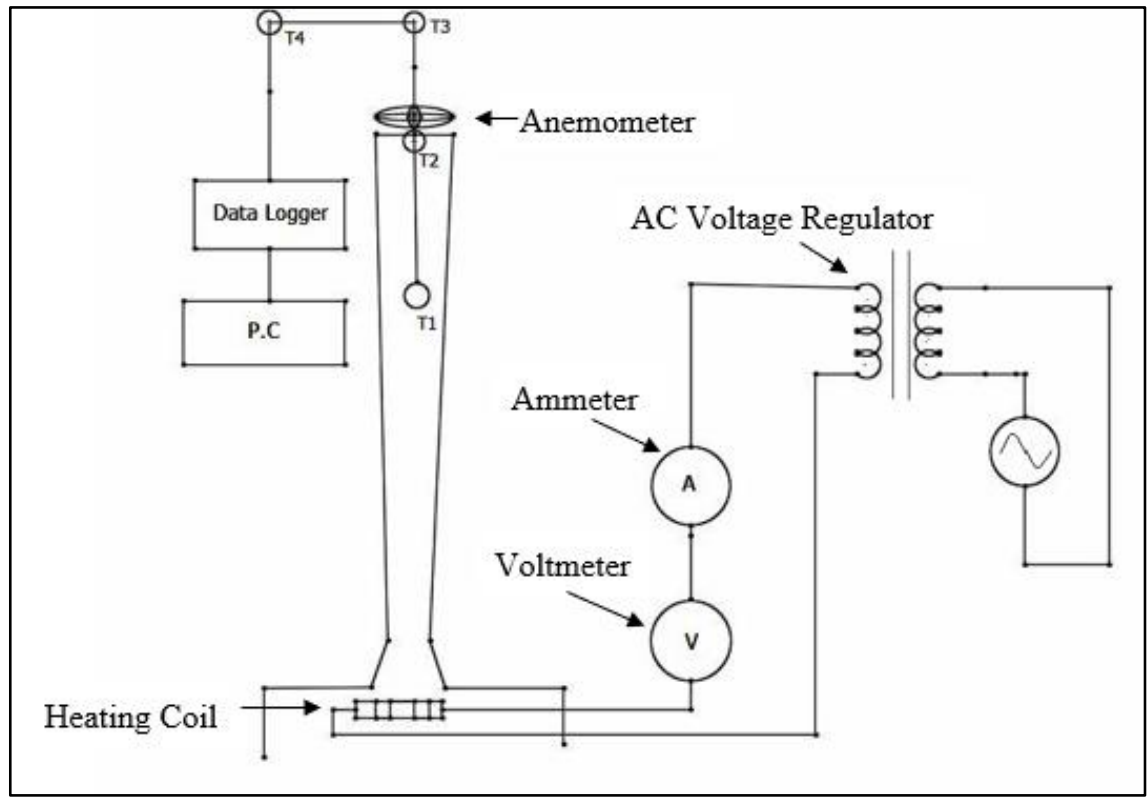

Fig. 3. Schematic Diagram of the Experimental Setup 
The performance of the chimneys was measured based on the operating parameter at various electric heat loads; $0.9 \mathrm{~kW}, 1.3 \mathrm{~kW}, 1.6 \mathrm{~kW}$ and $2 \mathrm{~kW}$. The temperature and air outlet velocity at the specified heat loads were measured and recorded. Density was calculated from the hot saturated air properties as shown in Eq. (5) using air properties between $0^{\circ} \mathrm{C}$ and $120^{\circ} \mathrm{C}$ for air properties at 1 atm pressure [5]. Air velocity at the throat was calculated using energy balance equation as shown in Eq. (6). The mass flow rate was calculated using Eq. (7).

$\rho=1 \mathrm{E}-05 \mathrm{~T}^{2}-0.0045 \mathrm{~T}+1.29$

$V_{1} A_{2}=V_{2} A_{2}$

$\dot{m}=\rho A_{c h} V$

The power potential of each solar chimney was calculated using Eq. (8) [3]. In the case of divergent shaped chimney, air velocity at the throat was further used for the theoretical power generation potential. Theoretical electric power generation was calculated using Eq. (9).

$$
\begin{aligned}
& P_{\text {wind }}=\frac{1}{2} \rho \times A_{\text {ch }} \times V^{3} \\
& P_{\text {electric }}=P_{\text {wind }} \times \eta_{t} \times \eta_{g}
\end{aligned}
$$

\section{Results and Analysis}

\subsection{Average Velocity}

Experiments were conducted on the different models of divergent and cylindrical chimney under different electric heat loads. Figure 4 represents the air velocity of divergent and cylindrical chimneys under different heat loads. The highest average velocities in the divergent and cylindrical chimneys were recorded under the electric heat load of $2 \mathrm{~kW}$ at $0.994 \mathrm{~m} / \mathrm{s}$ and $0.820 \mathrm{~m} / \mathrm{s}$ respectively in the $1 \mathrm{~m}$ configuration. The lowest average velocity of the cylindrical chimney was recorded as $0.41 \mathrm{~m} / \mathrm{s}$ while $0.49 \mathrm{~m} / \mathrm{s}$ was recorded in the divergent chimney at electric heat load of $0.9 \mathrm{~kW}$ and $2 \mathrm{~m}$ configuration. It is observed that the air velocity at the outlet decreases with an increase in solar chimney height. This is because the divergent chimney height from the throat and section area effect air velocity; shorter chimney tends to have shorter distance and smaller section area from the throat compared to a taller chimney.

Airflow in a solar chimney is explained through the concept of the stack effect. Amongst others, the stack/stack impact overall performance relies on temperature differences at the inlet and the top of the chimney. Thus, it is essential to analyze the temperature variations in the divergent and cylindrical solar chimney. All temperature measurement shows that divergent chimneys have greater temperatures differences compared to cylindrical chimneys as shown in Table 3. Maximum average temperature scale recorded was $55.4 \mathrm{~K}$ in the 1-meter divergent chimney as oppose to $38.9 \mathrm{~K}$ in the cylindrical chimney. This indicates that the divergent shape of chimney improves the stalk effect. 


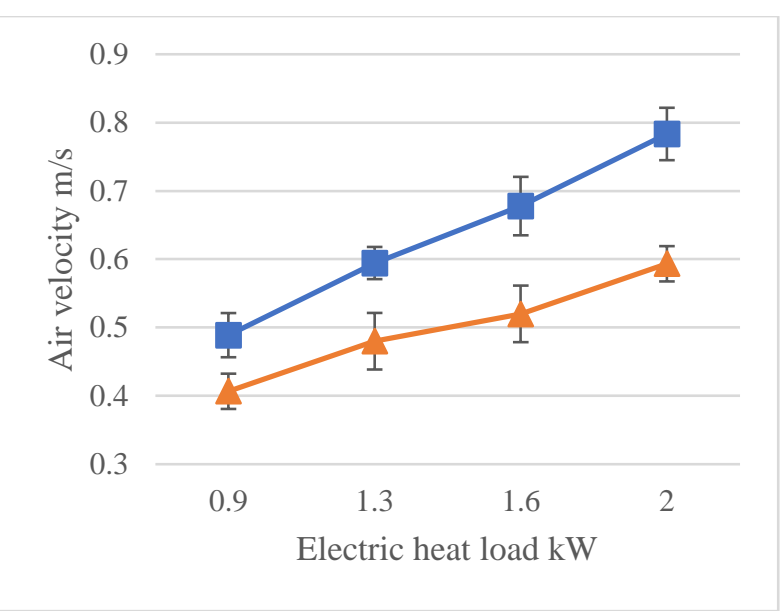

(a)

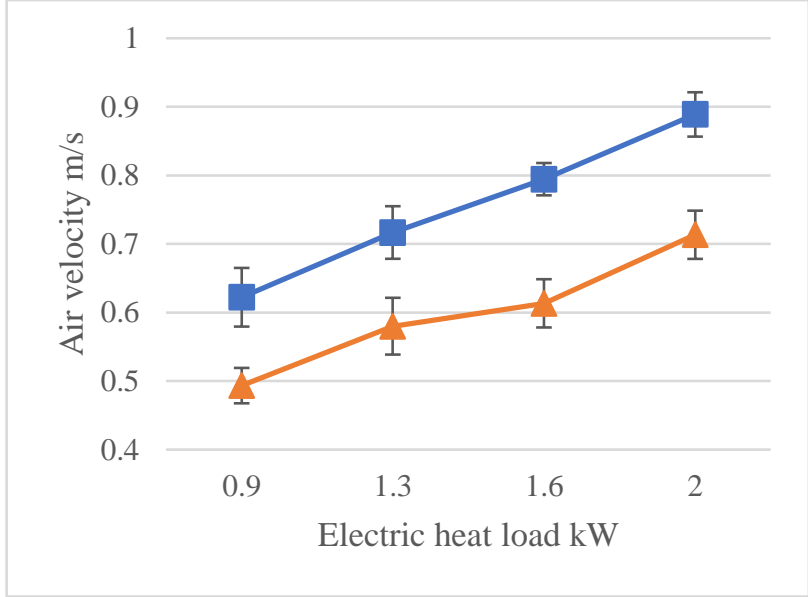

(b)

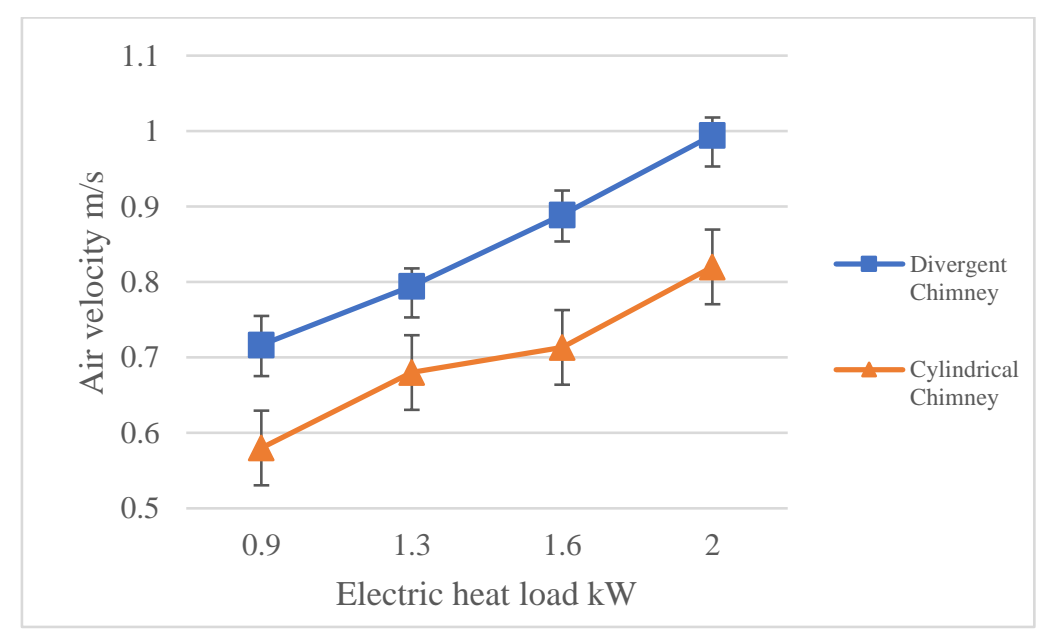

(c)

Fig. 4. Air Velocity Comparison of Divergent and Cylindrical Chimneys Under Different Electric Heat Loads (a) 2-Meter (b) 1.5-Meter (c) 1-Meter

Table 3

Outlet Temperature of the $1 \mathrm{~m}, 1.5 \mathrm{~m}$ and $2 \mathrm{~m}$ divergent and cylindrical chimney at different electric heat loads

\begin{tabular}{lllllllllllll}
\hline $\begin{array}{l}\text { Electric } \\
\text { heat } \\
\text { load }\end{array}$ & \multicolumn{3}{l}{$\begin{array}{l}\text { Outlet temperature in } \\
\text { divergent chimney, T2 }\end{array}$} & \multicolumn{3}{l}{$\begin{array}{l}\text { Temperature } \\
\text { difference with } \\
\text { inlet/ambient }\end{array}$} & \multicolumn{3}{l}{$\begin{array}{l}\text { Outlet temperature in } \\
\text { cylindrical chimney, T2 }\end{array}$} & $\begin{array}{l}\text { Temperature } \\
\text { difference with } \\
\text { inlet/ambient }\end{array}$ \\
\hline & $1 \mathrm{~m}$ & $1.5 \mathrm{~m}$ & $2 \mathrm{~m}$ & $1 \mathrm{~m}$ & $1.5 \mathrm{~m}$ & $2 \mathrm{~m}$ & $1 \mathrm{~m}$ & $1.5 \mathrm{~m}$ & $2 \mathrm{~m}$ & $1 \mathrm{~m}$ & $1.5 \mathrm{~m}$ & $2 \mathrm{~m}$ \\
$\mathrm{~kW}$ & $\mathrm{~K}$ & $\mathrm{~K}$ & $\mathrm{~K}$ & $\mathrm{~K}$ & $\mathrm{~K}$ & $\mathrm{~K}$ & $\mathrm{~K}$ & $\mathrm{~K}$ & $\mathrm{~K}$ & $\mathrm{~K}$ & $\mathrm{~K}$ & $\mathrm{~K}$ \\
0.9 & 341.9 & 330.1 & 326.5 & 38.9 & 27.1 & 23.5 & 334.9 & 324.1 & 320.2 & 31.9 & 21.1 & 17.2 \\
1.3 & 350.2 & 339.4 & 335.9 & 47.2 & 36.4 & 32.9 & 335.8 & 327.8 & 324.0 & 32.8 & 24.8 & 21.0 \\
1.6 & 354.5 & 341.1 & 337.6 & 51.5 & 38.1 & 34.6 & 339.2 & 330.7 & 326.0 & 36.2 & 27.7 & 23.0 \\
2 & 358.4 & 342.5 & 341.3 & 55.4 & 39.5 & 38.3 & 341.9 & 334.9 & 330.4 & 38.9 & 31.9 & 27.4 \\
\hline
\end{tabular}

Temperature measurement in the experiment shows that higher temperature data is recorded in shorter chimney configuration. This is because the collector size is kept constant at $0.8 \mathrm{~m}^{2}$ for all chimney models. Since a 1-meter chimney is smaller in footprint size compared to the $2 \mathrm{~m}$ chimneys (scaled), more surface area is available to heat the air inside the collector resulting in a higher temperature at the inlet. This higher temperature increases the buoyancy effect that increases air velocity in a short chimney model compare to tall chimney models. Furthermore, shorter chimney 
has fewer air frictions and thermal losses due to smaller size compared to the large-scaled chimney. Thus, the higher temperature difference in short scaled models causes higher air velocity due to the buoyancy [18]. Therefore, this greater temperature difference in short scaled cylindrical chimney models causes greater air velocity due to the fact of the buoyancy [18].

\subsection{Mass Flow Rate}

Mass flow rate is a crucial property to calculate the power potential of the chimneys. Although air velocity was higher in short-scale chimneys, the mass flow rate increases in line with the chimney scale. Figure 5 shows the mass flowrate in the 1, 1.5 and 2-meter divergent shaped chimneys. It is observed that the mass flowrate in the 1.5-meter divergent chimney is 1.5 times greater mass flowrate in contrast to 1-meter divergent chimney, whereas 2-meter divergent chimney has 1.5 times more mass flowrate in compared to 1.5-meter divergent chimney and 2.2 times greater compared to 1-meter divergent chimney using electrical heat load $2 \mathrm{~kW}$. Similar trends are observed in the case of the cylindrical chimney. The highest mass flow rate was calculated in the tallest chimney because of the big cross-section area though air velocity was low compared to small scale chimney.

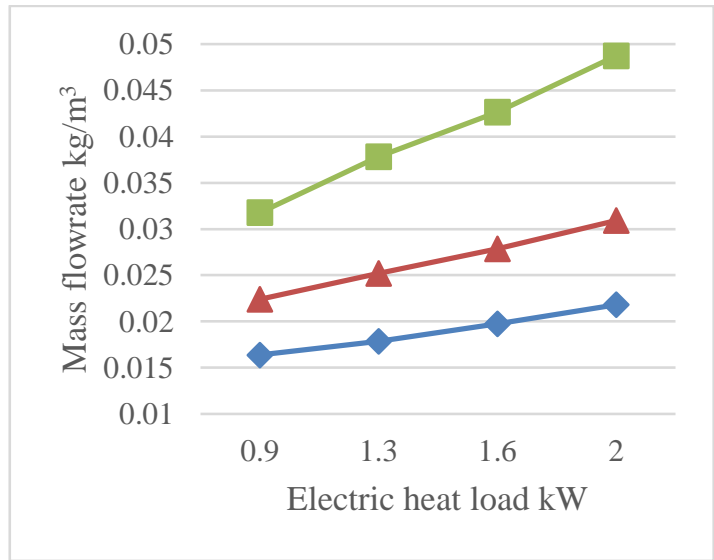

(a)

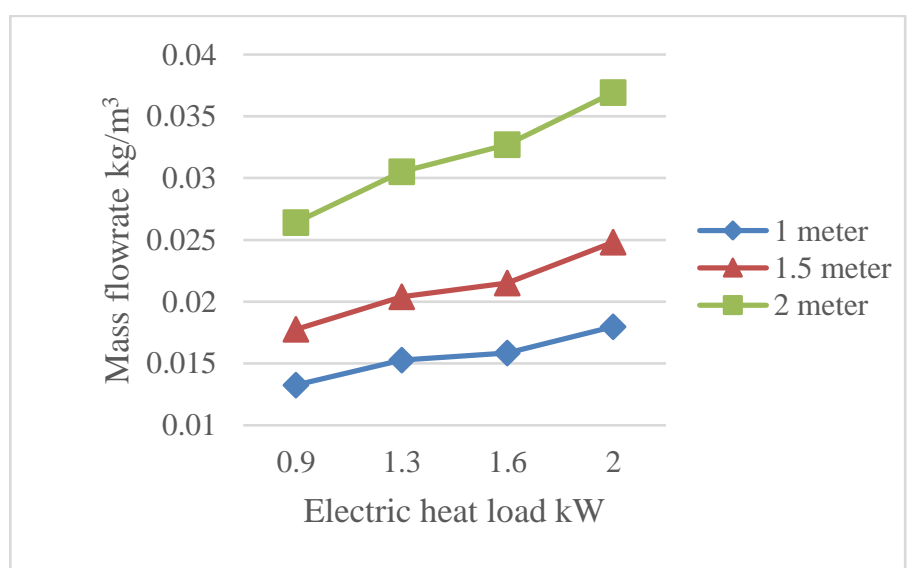

(b)

Fig. 5. Mass flowrate of (a) divergent chimney and (b) Cylindrical chimney under different electric heat loads

\subsection{Theoretical Electric Power Potential}

The experimental outcomes obtained from divergent and cylindrical chimneys were used to calculate the theoretical wind power potential using Eq. (9) and theoretical energy generation using Eq. (10). The results were compared with the electric heat load used in the divergent and cylindrical chimney experiment. Theoretical wind power potential increases with an increment of the electric heat load and height of chimneys. Also, the wind power potential is greater in the divergent solar chimneys compared to the cylindrical chimneys. Such behaviour occurs because the velocity at the throat in a divergent chimney increases due to a reduction of the area and results in greater kinetic energy compared to a straight cylindrical chimney [4].

The theoretical wind power potential was further used to simulate theoretical electric power generated by using Eq. (10); the turbine efficiency and generator efficiency was assumed at $85 \%$ and $90 \%$ respectively. Figure 6 and Figure 7 show the theoretical electric power generation for 3 different heights of the divergent and cylindrical solar chimney at various electric heat loads. Calculated data shows a large difference in theoretical power generated between 1-meter and 2-meter divergent chimney models which were not observed in cylindrical chimneys. The theoretical electric power 
generation of 1-meter chimney is 0.068 Watt whereas the 2-meter solar chimney is capable to generate 0.183 Watt at $2 \mathrm{~kW}$ electric heat load, a variance of $169 \%$. The larger cross-sectional area of the 2-meter chimney contributes to higher mass flow rate and in turn higher theoretical electric power potential. However, although cylindrical chimney does show an increase in theoretical power potential with chimney height increment; the increase was insignificant at $11 \%$.



Fig. 6. Theoretical Electric Power Generation in Divergent Chimneys

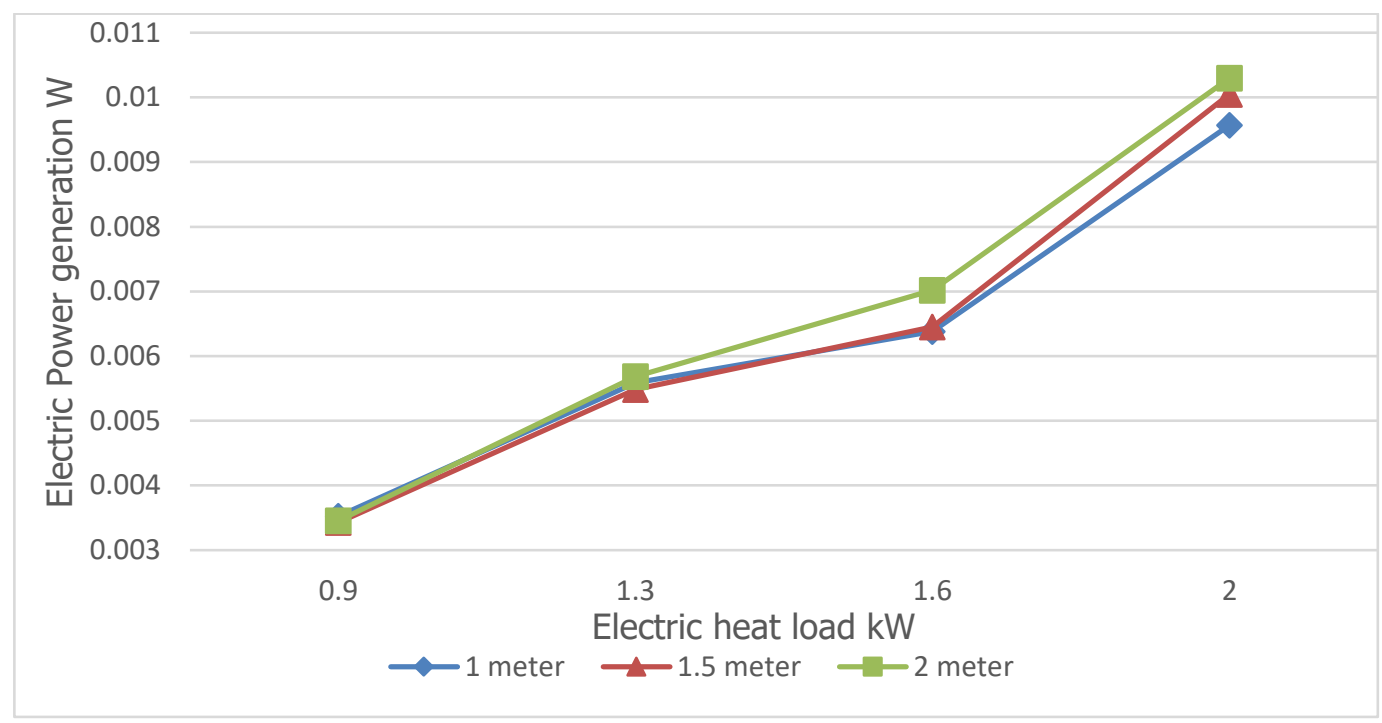

Fig. 7. Theoretical Electric Power Generation in Cylindrical Chimneys

The theoretical electric power generation shows that divergent chimney has a greater potential to generate higher electric power compared to a cylindrical chimney. This phenomenon is contributed to the pressure recovery mechanism within the divergent chimney due to the particular shape of its diffuser as critically analysed by some researchers [11,14]. The divergent chimney is 1.5 to 26 times more efficient compared to the cylindrical chimney depending on the parameters like the throat angle, chimney height and solar radiation intensity [10]. The results obtained from the current experiment shows 6 to 18 times better theoretical electric power generation in divergent chimney compared to cylindrical chimneys. 


\section{Conclusion}

This study has successfully measured experimentally the performance of divergent solar chimney in a laboratory condition and compared the result data with cylindrical chimney performance. The result shows divergent chimneys have better theoretical electric generation performance up to 18 times better compared to a cylindrical chimney at the same height ratio. At the highest electric heat load and tallest chimney, the theoretical electric power generation in a divergent chimney achieve 0.183 Watt whereas only 0.01 Watt was theoretically generated in a cylindrical chimney. The experiments also suggest that shorter divergent chimney has a greater electric power generation potential compared to the taller cylindrical chimney. Thus, a shorter divergent solar chimney suggests capital cost reduction while producing higher electric power. This study suggests that in the future, the experiments should be conducted with the following recommendation; use a different height of solar chimney using the same base area, using an actual wind turbine to generate electricity and to conduct experimental work in an actual condition.

\section{Acknowledgements}

The authors wish to convey sincere gratitude to Universiti Malaysia Sabah (UMS) for supporting the current research work thru UMSGreat research grant, project no. GUG0171.

\section{References}

[1] Ahmed, M. Rafiuddin, and Sandeep K. Patel. "Computational and experimental studies on solar chimney power plants for power generation in Pacific Island countries." Energy Conversion and Management 149 (2017): 61-78. https://doi.org/10.1016/i.enconman.2017.07.009

[2] Aurybi, Mohammed A., S. I. Gilani, Hussain H. Al-Kayiem, and Ali A. Ismaeel. "Mathematical evaluation of solar chimney power plant collector, integrated with external heat source for non-interrupted power generation." Sustainable Energy Technologies and Assessments 30 (2018): 59-67. https://doi.org/10.1016/i.seta.2018.06.012

[3] dos Santos Bernardes, Marco Aurelio, and Theodor W. von Backström. "Evaluation of operational control strategies applicable to solar chimney power plants." Solar Energy 84, no. 2 (2010): $277-288$. https://doi.org/10.1016/j.solener.2009.11.009

[4] Bouabidi, Abdallah, Ahmed Ayadi, Haytham Nasraoui, Zied Driss, and Mohamed Salah Abid. "Study of solar chimney in Tunisia: Effect of the chimney configurations on the local flow characteristics." Energy and Buildings 169 (2018): 27-38. https://doi.org/10.1016/j.enbuild.2018.01.049

[5] Cengel, Yunus. Heat and mass transfer: fundamentals and applications. McGraw-Hill Higher Education, 2014.

[6] Chakrabarti, Subrata K. "Chapter 13 - Physical Modelling of Offshore Structures." Handbook of Offshore Engineering (2005): 1001-1054. https://doi.org/10.1016/B978-0-08-044381-2.50020-5

[7] Fasel, Hermann, Ehsan Shams, and Andreas Gross. "CFD analysis for solar chimney power plants." In 9th International Conference on Heat Transfer, Fluid Mechanics and Thermodynamics, HEFAT 2012 (2012).

[8] Haaf, W., K. Friedrich, G. Mayr, and J. Schlaich. "Part I: Principle and Construction of the Pilot Plant in Manzanares." International Journal of Solar Energy 2, no. 1 (1983): 3-20. https://doi.org/10.1080/01425918308909911

[9] Hu, Siyang, and Dennis YC Leung. "Mathematical modelling of the performance of a solar chimney power plant with divergent chimneys." Energy Procedia 110 (2017): 440-445. https://doi.org/10.1016/i.egypro.2017.03.166

[10] Hu, Siyang, Dennis Y. C. Leung, and John C. Y. Chan. "Numerical modelling and comparison of the performance of diffuser-type solar chimneys for power generation." Applied Energy 204 (2017): 948-957. https://doi.org/10.1016/j.apenergy.2017.03.040

[11] Hu, Siyang, Dennis Y. C. Leung, and Michael Z. Q. Chen. "Effect of divergent chimneys on the performance of a solar chimney power plant." Energy Procedia 105 (2017): 7-13. https://doi.org/10.1016/i.egypro.2017.03.273

[12] Idelchik, Isaak E. "Handbook of hydraulic resistance." Washington (1986).

[13] Koonsrisuk, Atit, and Tawit Chitsomboon. "Effects of flow area changes on the potential of solar chimney power plants." Energy 51 (2013): 400-406. https://doi.org/10.1016/i.energy.2012.12.051

[14] Koonsrisuk, Atit, and Tawit Chitsomboon. "Mathematical modeling of solar chimney power plants." Energy 51 (2013): 314-322. https://doi.org/10.1016/i.energy.2012.10.038

[15] Kubo, Kazunori, Yoshiaki Miyazato, and Kazuyasu Matsuo. "Study of choked flows through a convergent nozzle." Journal of Thermal Science 19, no. 3 (2010): 193-197. https://doi.org/10.1007/s11630-010-0193-3 
[16] Papageorgiou, Christos. "Floating solar chimney technology." Solar energy (2010): 187-222. https://doi.org/10.2316/P.2011.714-052

[17] Pattanashetti, Jagadeesh S., and Madhukeshwara N. " Numerical Investigation and Optimization of Solar Tower Power Plant." International Journal of Research Inaeronautical and Mechanical Engineering 2, no. 1 (2014): $92-104$.

[18] Schlaich, Jörg. The solar chimney: electricity from the sun. Edition Axel Menges, 1995.

[19] Ubhale, Nilesh N., Lavendra S. Bothra, and Santosh R. Mallah. "Improving the Gained Power from Solar Chimney by Changing Radius and Height." International Journal on Recent Technologies in Mechanical and Electrical Engineering 3, no. 6 (2016): 09-18. 